\title{
Laparoscopic bilateral salpingo-oophorectomy as treatment for oestrogen dermatitis: a case report
}

\author{
Theofanis Manias • Costas Panayotidis • Nagui Aziz
}

Received: 29 March 2008 / Accepted: 13 May 2008/ Published online: 18 June 2008

(C) Springer-Verlag 2008

\begin{abstract}
We present a rare case of oestrogen dermatitis, which was successfully treated with laparoscopic bilateral oophorectomy. The mentality of medical and surgical treatment options is discussed.
\end{abstract}

Keywords Oestrogen dermatitis · Laparoscopic surgery · Laparoscopy $\cdot$ HRT

\section{Introduction}

Women can rarely become sensitised to steroid sex hormones. Sensitivity to progesterone is termed autoimmune progesterone dermatitis [APD] and has been well documented in the literature $[1,2]$. In contrast, oestrogen dermatitis has been recognised more recently and there are only few case reports describing this condition.

\section{Case study}

A 47-year-old woman presented to our gynaecological services with a 9-month history of a recurrent maculopapular eruption involving her face. The rash followed a cyclical pattern, flaring 3-days pre-menstrually and resolving spontaneously after the end of her period. She had three un-complicated pregnancies and no other gynaecological problems. The rest of her medical history was unremarkable and was not on any medication.

T. Manias $\cdot$ C. Panayotidis $(\bowtie) \cdot$ N. Aziz

Department of Obstetrics and Gynaecology,

Royal Oldham Hospital, Pennine Acute Hospitals NHS Trust,

Rochdale Road,

OL1 2JH Lancashire, UK

e-mail: costapan@hotmail.com
At the dermatology clinic, skin prick and intra-dermal testing were undertaken, in order to investigate whether these eruptions were hormonally related. A positive reaction was observed after intra-dermal injection of $0.5 \mathrm{ml}$ of Premarin ${ }^{\circledR}[10 \mathrm{mg} / \mathrm{ml}]$, while the test was negative for progesterone $[0.5 \mathrm{ml}$ of $10 \mathrm{mg} / \mathrm{ml}$ neat Gestone]. Controls with histamine and saline were appropriately positive and negative. Screening for auto-antibodies was negative for systemic lupus eruthematosus. The results from these investigations confirmed the diagnosis of autoimmune oestrogen dermatitis.

Initial treatment with monthly injections of goserelin $3.6 \mathrm{mg}$ [Zoladex $\left.{ }^{\circledR}\right]$ for a total period of 3 months resulted in complete resolution of her symptoms. After counselling the patient with regards to further management and available methods of treatment, she decided to have removal of both ovaries. An un-complicated three-port laparoscopic bilateral salpingo-oophorectomy was undertaken. No pelvic pathology was noted, both of her ovaries were normal and the patient was discharged the following day on Tibolone. In the 3-month follow-up appointment the dermatological symptoms had completely resolved.

\section{Discussion}

Oestrogen dermatitis was first reported by Shelley and colleagues in 1995, in a case series of seven patients [3]. Since then 24 more patients have been recognised with this condition [4-11]. It characteristically manifests as cyclical exacerbations of papulovesical lesions, utricaria, eczema or generalised pruritus. The symptoms tend to worsen premenstrually and have been described in response to both endogenous and exogenous oestrogens. The course of the condition is un-predictable and first symptoms may appear 
irrespective of the age of the woman. The management of oestrogen dermatitis appears rather challenging. Conservative treatment by means of discontinuation of exogenous oestrogen therapy is successful in most cases [3]. In cases of endogenous oestrogen sensitisation, the use of tamoxifen, a synthetic anti-oestrogen, has been shown to have the most promising results [4]. Tamoxifen most likely acts by competitive binding to the oestrogen receptor and thus, ameliorating the dermatological symptoms due to endogenous oestrogen. However, its use has been linked to endometrial hyperplasia, endometrial cancer and cervical polyps. There has been a single case report where the condition was successfully treated with the continuous progesterone contraception pill [10]. Moreover GnRH analogues have been used in the past with good response [11]. The side effects from their prolonged use and cost implications limit their long-term efficacy.

Surgical management of this rare condition has been reported sparingly in the literature. A single case has been described of a patient with suspected oestrogen dermatitis, who was treated with total abdominal hysterectomy and bilateral salpingo-oophorectomy [12]. To our best knowledge, our case is the first reported in the literature where laparoscopic surgical oophorectomy was performed.

The surgical decision should be made after thorough counselling regarding the uncertainties of long-term outcomes following a medical trial of GnHR analogues. The laparoscopic approach under experienced hands should be the first choice, due to the well-known benefits of shorter hospital stay, less post-operative pain and faster recovery.

The age of the patient is a significant parameter to be taken into account for therapeutic management. In young women fertility issues may need to delay or avoid any surgical treatment, hoping that a sort medical therapeutic trial may alleviate her symptoms. In both young and premenopausal women the need for hormone replacement therapy (HRT) after surgical treatment is a therapeutic dilemma. In our case, in order to avoid possible recurrence of the condition due to conventional low level oestrogen
HRT, we proposed Tibolone as an alternative. An allergic reaction to Tibolone is a possibility, however to our best knowledge no such case has been reported regarding the treatment of oestrogen dermatitis.

Oestrogen dermatitis is a rare entity and long-term outcomes of both medical and surgical treatments are not available. In our case long-term follow-up with yearly gynaecological consultation will be offered.

Acknowledgements The authors would like to thank Dr Kedia for her assistance to this case.

\section{References}

1. Shelley WB, Preucel RW, Spoont SS (1964) Autoimmune progesterone dermatitis, cure by oophorectomy. JAMA 190:35-38

2. Cocuroccia B, Gisondi P, Gubinelli E, Girolomoni G (2006) Autoimmune progesterone dermatitis. Gynecol Endocrinol 22 (1):54-56

3. Shelley WB, Shelley ED, Talanin NY, Santoso-Pham J (1995) Estrogen dermatitis. J Am Acad Dermatol 32(1):25-31

4. Leylek OA, Unlü S, Oztürkcan S, Cetin A, Sahin M, Yildiz E (1997) Estrogen dermatitis. Eur J Obstet Gynecol Reprod Biol 72 (1):97-103

5. Kim KH, Yoon TJ, Oh CW, Kim TH (1997) A case of estrogen dermatitis. J Dermatol 24(5):332-336

6. Kumar A, Georgouras KE (1999) Oestrogen dermatitis. Australas J Dermatol 40(2):96-98

7. Mutasim DF, Baumbach JL (2003) Bullous autoimmune estrogen dermatitis. J Am Acad Dermatol 49(1):130-132

8. Yotsumoto S, Shimomai K, Hashiguchi T, Uchimiya H, Usuki K, Nishi M, Kanekura T, Kanzaki T (2003) Estrogen dermatitis: a dendritic-cell-mediated allergic condition. Dermatology 207 (3):265-268

9. Murano K, Koyano T (2003) Estrogen dermatitis that appeared twice in each menstrual period. J Dermatol 30(10):719-722

10. Randall K, Steele R (2005) Estrogen dermatitis: treatment with progestin-only pill. Arch Dermatol 141(6):792-793

11. Yoon TY, Kim YG, Kim MK (2005) Estrogen dermatitis responding to leuprolide acetate. J Dermatol 32(5):405-406

12. Mayou SC, Charles-Holmes R, Kenney A, Black MM (1988) A premenstrual urticarial eruption treated with bilateral oophorectomy and hysterectomy. Clin Exp Dermatol 13(2):114-116 